\title{
Assessment of Treatment from the National Laboratory of Cholera Patients in Benin: Retro-Prospective and Prospective Study
}

\author{
Bawa Boya', Théodora A. Ahoyo², Victorien T. Dougnon³, Haziz Sina1, Odilon Nonfodji2, \\ Wassiyath Moussé ${ }^{1}$, Adolphe Adjanohoun ${ }^{4}$, Lamine Baba-Moussa ${ }^{*}$
}

${ }^{1}$ Laboratoire de Biologie et de Typage Moléculaire en Microbiologie (LBTMM). University of Abomey-Calavi, Cotonou, Benin ${ }^{2}$ Génie de Biologie Humaine/Ecole Polytechnique d'Abomey-Calavi (EPAC), University of Abomey-Calavi, Cotonou, Benin ${ }^{3}$ Unité de Recherche en Microbiologie Application et Pharmacologie des substances Naturelles (URMAPha), University of Abomey-Calavi, Cotonou, Benin ${ }^{4}$ Institut National des Recherches Agricoles du Benin, Cotonou, Benin Email: *laminesaid@yahoo.fr

How to cite this paper: Boya, B., Ahoyo, T.A., Dougnon, V.T., Sina, H., Nonfodji, O., Moussé, W., Adjanohoun, A. and Baba-Moussa, L. (2020) Assessment of Treatment from the National Laboratory of Cholera Patients in Benin: Retro-Prospective and Prospective Study. Advances in Microbiology, 10, 443-455.

https://doi.org/10.4236/aim.2020.109033

Received: July 17, 2020

Accepted: September 19, 2020

Published: September 22, 2020

Copyright $\odot 2020$ by author(s) and Scientific Research Publishing Inc. This work is licensed under the Creative Commons Attribution International License (CC BY 4.0).

http://creativecommons.org/licenses/by/4.0/

\begin{abstract}
Cholera is re-emerging as an infectious disease with an increase in its overall incidence in Africa since 2008. To analyze the epidemiological aspects of the cholera outbreak in endemic areas in Benin, the study is a retrospective investigation on 2560 data of cholera patients received in health facilities from 2012 to 2016 in Benin. Besides, a prospective study was conducted. This prospective study includes 513 person (health professionals, community workers and people exposed to cholera) of five different areas of the country. It was conducted from April 10 to May 10, 2017. A survey was conducted over 513 in order to collect data on cholera symptoms, hygiene guidelines suggested by the respondents, excreta disposal, drinking water, household waste management and direct observation. Software R 3.4.0 was used for simple correspondence factor analysis (CFA). From 2012 to 2016, 16.48\% of samples were taken and $48.34 \%$ were positive for Vibrio cholerae O1, El Tor biotype, Ogawa serotypes. The Littoral area is leading in the number of cases (33.83\%) followed by Atlantic (23.75\%), Ouémé (16.79\%) and Colline (8.91\%). The survey revealed that the exposed populations are unaware of the symptoms of cholera and do not perceive the quality of drinking water as a strong guidance in the prevention of cholera. Nevertheless, the majority of respondents (86\%) are aware for the best times to wash their hands and know that they need to go to hospital in case of symptoms. Our study highlights the persistence of vulnerability factors to cholera in the targeted population, despite a good knowledge of prevention rules among staff and the population.
\end{abstract}




\section{Keywords}

Cholera, Hygiene Guidelines, Practices and Preventions, Benin

\section{Introduction}

Cholera is an acute diarrheal bacterial infection caused by the Gram-negative bacillus Vibrio cholerae, which produces a toxin responsible for the symptoms associated with the disease. More than 200 serogroups of Vibrio cholerae have been identified, but only two of them, $\mathrm{O} 1$ and $\mathrm{O} 139$, are associated with clinical cholera syndrome capable of producing large epidemics. It is endemic in the humid tropics of Africa and Asia and epidemic in some Latin American countries as well as in dry areas [1]. According to the World Health Organization (WHO), there are 3 to 5 million cases of cholera, with 100,000 to 120,000 deaths, each year worldwide. Africa is the most affected continent: reported cases represent between $95 \%$ and $99 \%$ of the world total each year [1]. This disease is due to uncleanliness and poor hygiene conditions occurring in communities with low living standards [2]. Surveillance and response are part of the strategy to control diseases with epidemic potential, including cholera proposed by WHO to affected countries [3].

In Benin, this epidemic appeared in 1970, then became almost annual, and generally occurs at the end of the rainy season [4]. Between 2004 and 2013, epidemiological surveillance reported 5432 cases with 48 deaths, a case-fatality rate of $0.9 \%$ [5]. In response to these cholera epidemics, a series of actions have been deployed, including hygiene awareness among the families of patients, decontamination of homes with chlorinated water, occasional sanitation actions, prophylaxis of the patient's environment and a single dose of doxycycline [3]. However, the socio-economic and sanitary conditions in some areas at risk of cholera (Abomey-Calavi, So-ava, Parakou, Savalou, Cotonou, Athieme, Porto-Novo, Seme-Kpodji, Aguégués, Djougou and Dangbo) slow the application of the planned hygiene and sanitation guidelines, and cholera is recurrently evolving in endemic mode in these areas. The objective of this work is to analyze the epidemiological aspects of the cholera outbreak in endemic areas in Benin.

\section{Material and Methods}

\subsection{Study Area}

The surveys were conducted in health facilities located, between April and May 2017, in five departments (Ouémé, Atlantic, Littoral, Colline and Donga) of Benin (Figure 1).

Climatic factors such as flooding during the rainy seasons can have an immediate impact on the spread of the cholera epidemic in duration and space. In Cotonou and the surrounding area, the floods are the result of the flooding of the Ouémé River and its tributary Lake Sô. Lake Nokoué regularly overflows up 


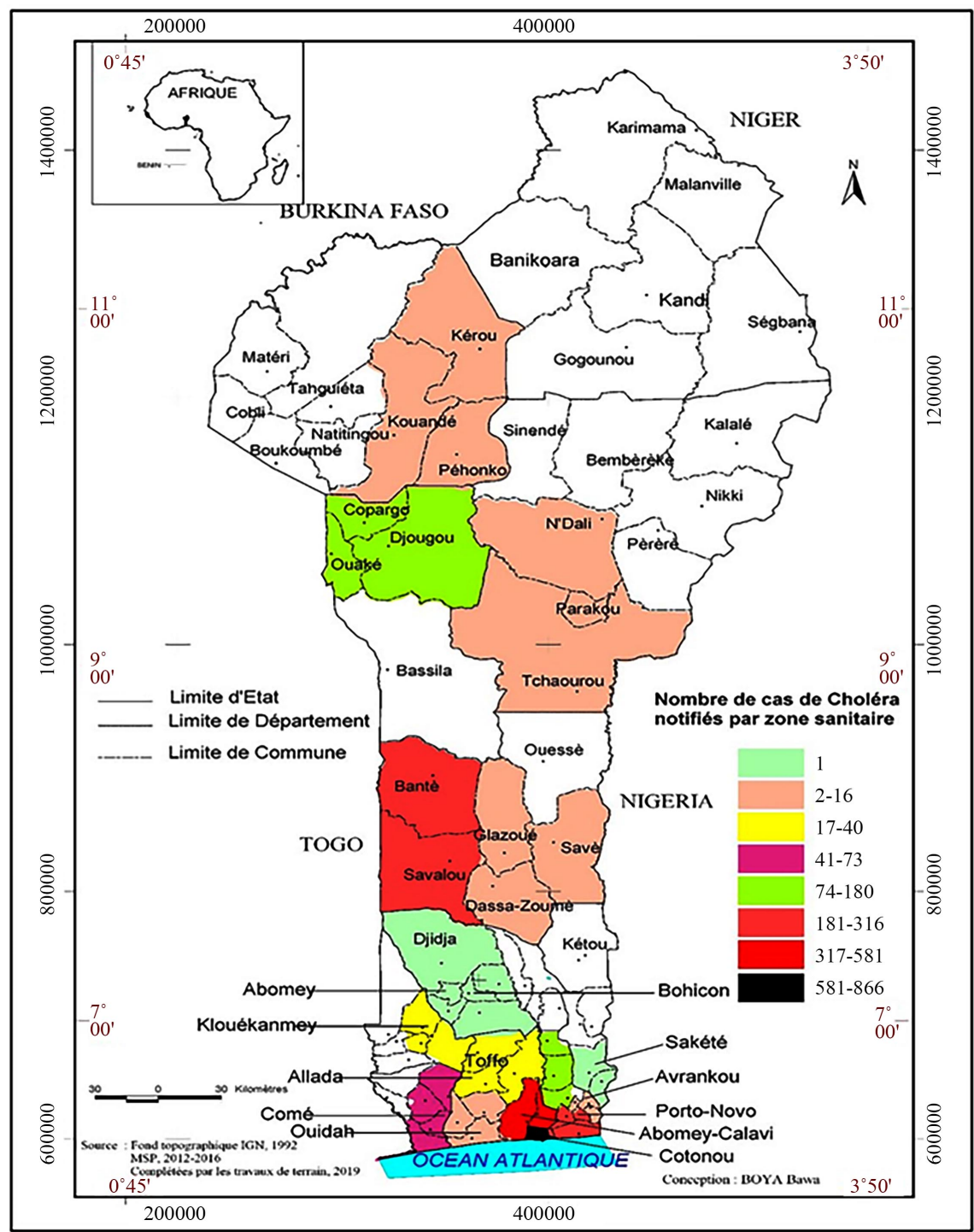

Figure 1. Map showing cholera-affected areas from 2012 to 2016.

to the $1.50 \mathrm{~m}$ contour line. The water table rises, causing increased retention of runoff water by artificial dams (rails, roads, dwellings and embankments), and isolation of areas without natural outlets [6] (Direction Nationale de la Santé Publique du Bénin, 2017). During the 2010 floods, which caused latrine water to spill over the flooded garbage dumps, there was a strong spread of waterborne and hydro-fecal diseases. The flooding phenomenon is worsening in the "cities" of Grand Nokoué (Abomey-Calavi, Cotonou, Sèmè-Podji and Porto-Novo) where there are still cases of anarchic occupation of the lowlands and even natural water outlets by the population. This is the case of the Cotonou lagoon bank, which is a highly vulnerable zone to cholera. In the long term, climate change linked to global warming may interact with seasonal climatic factors, particularly through climatic anomalies, and can be the cause of major epidemic outbreaks [6]. The study took into account the endemic zones that have concentrated more than $80 \%$ of cholera cases in Benin in five years according to the epidemiological 
report of the Ministry of Health of Benin [5]. These areas are characterized by the presence of lakes and lagoons that favour the environmental survival of cholera vibrio. Similarly, conditions of access to water and sanitation are very precarious.

\subsection{Type of Study}

This is a retrospective and prospective study. The retrospective study focused on the clinical reports of the Ministry of Health. These reports were those that had at least information on patient identity, neighborhood of origin, date of entry, diagnosis, treatment and clinical status at discharge. A prospective study complemented the hygiene and sanitation clinical reports. It was carried out in 2017 and took into account health workers and endemic populations.

\subsection{Data Collection}

The data were collected in health centers in the five departments of Benin. A town was selected per department. In general, these cities are regularly affected with a duration and incidence ranging from medium to high. Thus, the data was collected in the health centers of the different health zones of cities inside Benin namely Abomey-Calavi (Atlantic), Cotonou (Littoral), Porto-Novo (Ouémé), Sèmè-Podji (Ouémé), Dassa-Zoumé (Colline), Savalou (Colline) and Djougou (Donga). Sixteen (16) public health centers were included in this study. The methodology used for data collection varied according to the type of study.

In the case of retrospective study, the strategy adopted was to consult the databases (2012 to 2016) of the targeted hospitals. For this purpose, data of 2560 patients were consulted. The data sought from these databases were the number of cases, deaths and laboratory results. In the case of prospective study, a random sampling was carried out. Data were collected using an individually addressed questionnaire in a single pass at the study population. The collected data are related to the level of cholera knowledge about, prevention attitudes and practices and environmental structure. An interview was used to assess the level of knowledge about cholera as well as attitudes and practices in terms of prevention. The sample size was determined using the formula of Schwartz [7] with a confidence level of $95 \%$, a margin of error of $4 \%$ and a prevalence $(25 \%)$ of cholera cases in water. according to WHO [8]. This gave us a minimum height of 195. A $14 \%$ increase was made and gave a final size of 513 for the interview.

\subsection{Statistical Analysis}

Knowledge of cholera, its causes and methods of prevention are very much influenced by the different target groups. For this reason, the subjects surveyed were grouped into seven target groups. For each group, the number of people who opted for each of the perceptions identified was calculated. These types of perceptions are essentially cholera, Symptoms, Hygiene measures proposed by the respondents, Excreta disposal, Drinking water, Mode of household waste management of the respondents. The resulting contingency table was subjected 
to simple correspondence factor analysis with the "CA" function of the "Facto Mine R" package [9] using R 3.4.0 software [10].

\section{Results}

The cross-sectional descriptive study allowed us to distribute the population according to several criteria: age, sex, education level, knowledge about cholera disease, cholera prevention measures and cholera treatment.

\subsection{Medico-Clinical Aspects}

Table 1 presents the distribution of clinical cholera cases during the 2012-2016 epidemics in Benin and the results of associated stool samples. A total of 422 samples were taken from 2626 identified clinical cases, i.e. a collection rate of $16.48 \%$. Of the 422 samples $204(48,34 \%)$ were tested positive to Vibrio cholerae O1, El Tor biotype, Ogawa serotypes (Table 1).

\subsection{Epidemiological Aspects of Cholera in Benin between 2012 and 2016}

Epidemiologically, there is a variation in the age of the patients, but overall, the most infected age group is between 16 and 20 years of age. Thus, the average age of infected was 28 years while the median age was 27 years and the maximum age was 76 years. People aged 5 years old and up accounted for $92 \%$ of the total number of cases. The sex ratio of males to females is 1.1. From 2012-2016, the average cholera case-fatality rate was $1.05 \%$. Note that the lowest rate $(0.5 \%)$ was recorded in 2012 and the highest rate (1.7\%) was observed in 2016 (Figure 2). Considering areas, it appears that Littoral had the highest rate $(33.83 \%)$ of cholera cases between 2012 and 2016 followed by Atlantic (23.75\%), Ouémé (16.79\%), and Colline (8.91\%) (Figure 1).

\subsection{Characteristics of the Population (Prospective Study)}

In this study, out of 513 enrollees, all responded and are included in the study. This number corresponds to all the people present in the health care structures in the endemic areas visited and who agreed to participate in the survey. They are 138 health personnel including health care assistants (40), nurses (40), laboratory technicians (23), hygienists (23) and doctors (12), community relays (50) as well as the exposed population (325). The majority of respondents are women $56 \%(288 / 513)$ against $44 \%(225 / 513)$ men and therefore a sex ratio $\mathrm{M} / \mathrm{F}=0.78$. They are mostly Christians 70\%, a small proportion of Muslims 26\% and the rest $4 \%$ animists and others.

The survey shows that $58 \%$ of the respondents use the Fongbé language as their first spoken language against $40 \%$ who speak it as a second language. About $35 \%$ of the respondents speak Yoruba as their first language against 18\% who use it as a second language. French is used by $32 \%$ of respondents as a second language spoken. Approximately $37 \%$ of respondents had at least primary school education, $21 \%$ were not educated. Table 2 shows the distribution of 


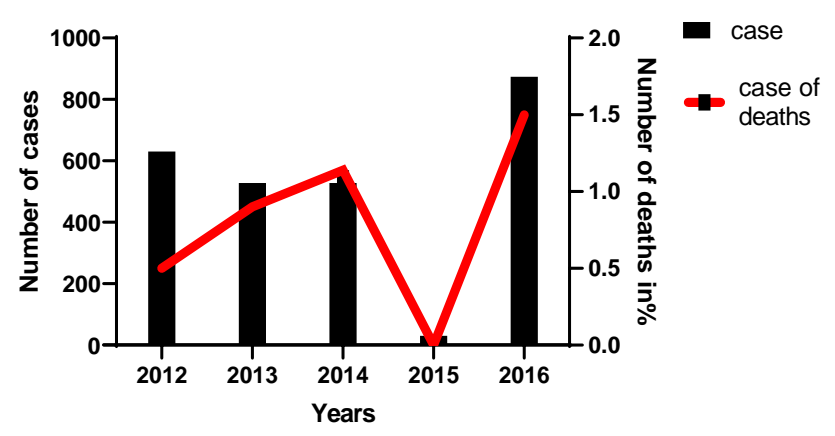

Figure 2. Number of cholera cases and case-fatality by year 2012 to 2016.

Table 1. Summary of levies for 2012-2016.

\begin{tabular}{ccccc}
\hline Year & $\begin{array}{c}\text { Number of identified } \\
\text { clinical cases }\end{array}$ & $\begin{array}{c}\text { Number of saddles } \\
\text { collected and analyzed }\end{array}$ & $\begin{array}{c}\text { Presence of } \\
\text { Vibrio cholerae }\end{array}$ & $\begin{array}{c}\text { Absence of Vibrio } \\
\text { cholerae }\end{array}$ \\
\hline 2012 & 630 & $57(9.05 \%)$ & $38(66.67 \%)$ & $19(33.33 \%)$ \\
2013 & 528 & $66(12.5 \%)$ & $32(48.50 \%)$ & $34(51.5 \%)$ \\
2014 & 528 & $66(12.5 \%)$ & $32(48.50 \%)$ & $34(51.5 \%)$ \\
2015 & 0 & 66 & $32(48.50 \%)$ & $34(51.5 \%)$ \\
2016 & 874 & $167(5.23 \%)$ & $70(41.92)$ & $97(58.08)$ \\
Total & 2560 & $422(16.48 \%)$ & $204(48.34 \%)$ & $218(51.66 \%)$ \\
\hline
\end{tabular}

Table 2. Education level of respondents.

\begin{tabular}{ccccc}
\hline Education level of respondents & Pop (\%) & P (\%) & Rel (\%) & Average (\%) \\
\hline uneducated & 42.2 & 5.1 & 15 & 20.77 \\
Primary education & 37.3 & 25.4 & 40 & 34.23 \\
Secondary & 19.2 & 32.5 & 30 & 27.23 \\
University & 1.3 & 37 & 15 & 17.77 \\
Total & 100 & 100 & 100 & 100 \\
\hline
\end{tabular}

Rel: community relays; P: health personnel; Pop: populations exposed to cholera.

the interviewees according to education level. The average age of the respondents is $31-40$ years old and $12 \%$ are over 50 years old. The youngest is 18 and the oldest is 60 .

\subsection{Community Knowledge of Cholera, Its Causes and Methods of Prevention}

The Factorial Analysis of simple Correspondences (Figure 3) highlighted the link between the target groups of the study and their perception of the knowledge of cholera, its causes and methods of prevention. Indeed, these results show that the first two factorial axes concentrate $78.13 \%$ of the total information (Table 3). It appears from the analysis of Figure 3 that the populations not exposed to cholera (PEC_N) have a very good knowledge of the definition of cho- 
lera (Con_Def), this level of knowledge leads them to take certain measures in the direction of prevention against the disease. On the other hand, populations exposed to the disease (PEC_O) who even have some knowledge of the disease (cholera) do not take adequate measures for the prevention of the disease. In fact, the contribution of these variables in relation to the factor axes shows that populations exposed to cholera (PEC_O) evacuate their excreta in the open air (EE_AL) and use water from unprotected wells as drinking water (EB_PNP) and use garbage heaps (MGOM_TO) as a mode of household waste management. Moreover, in this same group of individuals (exposed populations) a rate of 74.65\% has no knowledge of the disease (PEC_NSP). The projection of these variables (PEC_NSP) on the AFC axes shows that this group of individuals is

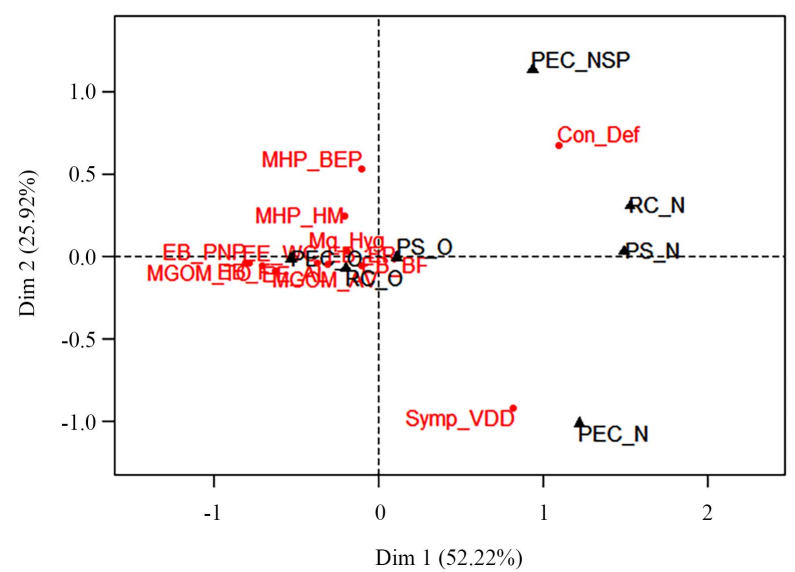

Figure 3. Perception of target groups related to knowledge of cholera and its causes and methods of prevention: projection of target groups in the factorial axis system following a Factor Correspondence Analysis. Legend: Con_Def: Cholera is an acute contagious diarrhoeal infection due to Vibrio cholerae, Mq_Hyg: Lack of hygiene; Symp_VDD: Symptoms_diarrhoea, vomiting and dehydration; MHP_HM: Proposed hygiene measures_Hand hygiene; MHP_BEP: Proposed hygiene measures_Drinking of drinking water; EE_WC: Disposal of excreta_WC; EE_AL: Disposal of excreta in the open air; EB_ER: Drinking water_ Tap water; EB_PNP: Drinking water_Unprotected well; EB_F: Drinking water_River; EB_BF: Drinking water_ Fountain stand; MGOM_TO: Mode of household waste management_Sanitation; MGOM_AV: Mode of household waste management_Sanitation.

Table 3. Own values and percentage of information concentrated on the axes.

\begin{tabular}{cccc}
\hline Dimensions & Own values & ratios of individual values & Accumulates percentages \\
\hline Dim1 & 0.43 & 52.22 & 52.22 \\
Dim2 & 0.21 & 25.92 & 78.13 \\
Dim3 & 0.14 & 16.48 & 94.61 \\
Dim4 & 0.04 & 4.58 & 99.20 \\
Dim5 & 0.01 & 0.80 & 100.00 \\
Dim6 & 0.00 & 0.00 & 100.00 \\
\hline
\end{tabular}


more aware of the symptoms of cholera (Symp_VDD) but do not perceive the fact of drinking water (MHP_BEP) as a hygiene measure to be proposed.

\subsection{Treatment of Cholera}

When the necessary arrangements are not made for the prevention of the disease, sick individuals need curative treatment. Several approaches are used in the treatment of the disease. Indeed, the objective of this part of the study is to assess the level of knowledge of the different target groups on the approaches used in the treatment of cholera. The analysis of the results shows that 04 approaches are generally used. These are rehydration, the use of phytotherapy with medicinal plants, antibiotics (adequate or not) uses and ORS. In addition, $68.25 \%$ of the population has no knowledge of the approaches used in the treatment of cholera. On the other hand, $70 \%$ of health staff and $58 \%$ of Community Relays say that the best treatment to cure cholera is oral rehydration. Figure 4 presents the distribution of the interviewees according to their knowledge on cholera treatment.

\section{Discussion}

The population concerned by the care of cholera patients in Benin is the population admitted to cholera treatment centers during the 2012-2016 cholera epidemic present in endemic areas. These areas are characterized by the presence of lakes and lagoons that favor the environmental survival of cholera vibrio in the departments of Littoral, Atlantic, Ouémé and Mono. Similarly, the conditions of access to water and sanitation are very precarious in the departments of Colline, Donga and Borgou. Other important risk factors such as the presence of pigs, markets and at-risk populations such as fishermen and traders, who are the ideal vector of the disease, are present there [6]. The evolution of the epidemic during the year was classic with a resurgence in 2016, the same observation was made in DRC where 22,002 cases were reported compared to 2015 (12,269 cases) [11]. This spike is thought to be due to various factors that may influence the number of cases and deaths reported, including a weak surveillance system, the use of inappropriate case definitions, inadequate laboratory diagnostic capacity and reluctance to report for fear of negative economic consequences. Also problematic is

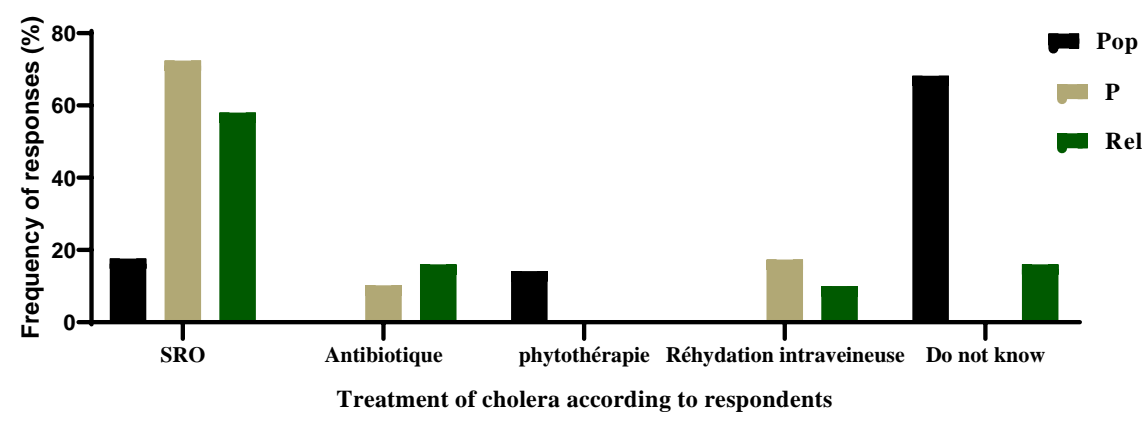

Figure 4. Knowledge of the study population on cholera treatment. Rel: community relays; P: health personnel; Pop: populations exposed to cholera; SRO: oral rehydration solution. 
the lack of a national case management protocol with clear guidelines based on WHO recommendations. The observation was made during the 2016 epidemic; management varies from one health zone to another on certain aspects.

Clinically, the epidemic has affected mostly adolescents and adults (92\%). These results are consistent with those of Ndour et al. [12] in Senegal, Dray et al. [13] in Djibouti, and Khazaei et al. [14] in Iran, where the epidemic has affected mainly adolescents and adults, who constitute the most active segments of the population. These people eat lunch at their workplaces, at school or at food vendors and are thus exposed to cholera. The people most affected are female traders. Our results are contrary to those obtained by other authors where they found a slight male predominance [12] [13] [15], probably due to the fact that men often have easier access to health care compared to women. Indeed, women are the main actors in this market where they sometimes spend several days and nights in poor accommodation and catering conditions. The burden and consequences of cholera epidemics are significant in Benin, where the case-fatality rate exceeded the 1\% threshold (1.1\%) between 2012 and 2016. However, in 2016 there is an increase in the lethality rate to $1.7 \%$. Therefore, this figure calls for vigilance, community surveillance and the strengthening of measures for proper care in all the formations empowered to treat cholera cases, including private health facilities.

Bacteriologically, of the 422 stool samples found in the laboratory, 204 were positive for Vibrio cholerae O1. Our results are higher on the sampling rate than those obtained by Makoutode et al. [3] in Benin where they found a rate of 9.95\% (40/402) forwarded samples but found 95\% positive for Vibrio cholerae O1 biotype El Tor. This is higher than our results, which were $48.34 \%$. These results are believed to be due to difficulties in getting samples from the health zones to the national laboratory for confirmation after at least 48 hours, lack of reagent and sample size. This and the lack of reagents at the national laboratory did not favor a rapid response. However, the laboratories of some hospitals in the zones concerned had carried out local examinations enabling the zone management teams to initiate response actions while waiting for confirmation from the national laboratory [6]. According to WHO [16], biological confirmation of the first 10 - 20 cases is essential to ensure that it is a cholera outbreak. Once the outbreak is confirmed, it is not essential to collect a sample from every patient with acute diarrhea: clinical case definition allows detection of cholera and appropriate treatment. Nevertheless, it may be worthwhile to collect a few random samples during the outbreak to ensure that the pathogen's susceptibility to antimicrobials has not changed. Subsequently, approximately 20 stool samples should be collected to confirm the end of the outbreak, as it is not Vibrio cholerae $O 1$ alone that produces bloody stools, but also Shigella dysentery type 1.

In addition, in 2015 the laboratory reported positive cases of cholera that were not reported by the surveillance cell. This could be due to a lack of coordination between the laboratory and the surveillance cell. The results of the survey show that there are gains in the respondents' knowledge and practices to prevent cho- 
lera in Benin. For example, most respondents (86\%) are aware of the best time to wash their hands and the option of going to a health center in case of cholera. Nevertheless, respondents do not know the main reason for handwashing with soap and water, although $70 \%$ of them say it is the easiest awareness message to practice. This observation is not a good behavior as it was reported in Haiti that water might be the major risk factor in the transmission of cholera during an early epidemic [17] [18] [19].

Hand hygiene, which is one of the basic effective and efficient measures to prevent the spread of diarrhea infections including cholera according to WHO [16] is not properly observed including among health workers. This observation would be linked, among other things, to a lack of in-service training plan and supervision oriented towards managerial and technical aspects. This situation generates confusion at the level of the messages addressed by the providers to the population on cholera. The health structures that we visited are very poorly equipped, and the systems put in place are inadequate for proper practice. There are not enough health workers. At the level of the exposed population, the level of education and/or literacy in a national language is low (more than $21 \%$ are not educated) and constitutes a handicap to assimilate the different awareness messages. Populations exposed to this disease dispose of their excreta in the open air. They also use water from unprotected wells as drinking water and use garbage heaps as a way of managing household waste. These behaviors could be important factors conducive to this epidemic outbreak. This situation is also due to the inadequate implementation of the national hygiene and sanitation policy and the lack of sanitation facilities and garbage management equipment. Half of the people surveyed said they throw household waste out into the open because the household waste disposal system is deficient in Benin's cities. One of the consequences is the visible presence of several uncontrolled dumps that become defecate places. Existing rainwater drainage channels are transformed into faecal and garbage dumps. Thus, during the rainy season, runoff water drains faecal matter into certain uncovered and uncovered wells that are sources of drinking water supply for the populations (for 30\% of the respondents). Legba et al. [20] in Benin reported the same situation. Jaureguiberry et al. [21] and Dao et al. [2] also observed this phenomenon in Madagascar and Mali respectively. These shortcomings could explain the persistence of certain behaviors unfavorable to the individual and collective hygiene of populations and justify the recurrence of epidemics. Moreover, according to the OCS report in 2013 in Benin, 13.2\% of households dispose of garbage through public or private roads, which means that $86.8 \%$ of households in Benin continue to throw garbage in the wild. The same situation arises in terms of toilet use since, according to the same survey data; only $41.9 \%$ of households use latrines for excreta disposal. It emerges that more than half of Benin's population continues to "make themselves comfortable" in the open air. This poses a real sanitation problem for the Beninese population. 
Cholera control in African countries is mainly focused on disease surveillance and epidemic response according to Makoutodé et al. [3], Ndour et al. [12]. Two consequences can be drawn from this strategic choice: on the one hand, the vulnerability of all African countries reflects similar socio-economic conditions characterized by insufficient investment by the States for the improvement of the living environment of the populations. On the other hand, we are witnessing a reduction in the case-fatality rate, due to the importance given to medical care [3]. The impact of these actions on the communities in the medium and long term remains very marginal. Emphasis is placed on the management of epidemics, whereas the socio-economic determinants of cholera do not seem to be the subject of public action.

Cholera is a diarrhea disease, which can be caught by either drinking contaminated water or eating contaminated food, and is easily treated. This message is known by $68 \%$ of respondents, since they will choose to bring a sick relative to the hospital, only $42 \%$ do not believe in free treatment. Indeed, the destitution of health centers means that sometimes-false fees are created for the functioning of the health center, making free care ineffective. Hygiene measures made possible to eradicate cholera in developed countries, whereas in countries with limited resources, the improvement of hygiene levels is far from being achieved for economic and socio-cultural reasons [22] [23] [24].

\section{Conclusion}

Our study shows that the population studied has a varied notion of cholera despite its frequency in their area. Although basic hygiene and sanitation measures have proven to be effective in preventing diarrhea diseases and cholera in particular, compliance is low, especially among health professionals. Fecal peril remains a persistent problem in the study area. The production of messages in this regard should be a necessity in order to inform and sensitize the population. Basic hygiene measures are known, however, the level of poverty of the people living in the areas visited does not allow them to comply with the required hygiene standards. These factors are clear risks for the spread of cholera.

\section{Ethic Consideration}

Health officials in the region agreed. In addition, all participants gave their consent after knowing the purpose of the survey. A secret ID identified each household.

\section{Acknowledgements}

We address our sincere thanks to the health actors, community workers, the exposed population and those who assisted us in carrying out this work.

\section{Conflicts of Interest}

The authors declare no conflicts of interest regarding the publication of this paper. 


\section{References}

[1] Rossant-Lumbroso, J., Rossant, L., Cardenas, J. and Pujol, M. (2018) Choléra. http://www.doctissimo.fr/html/sante/encyclopedie/ sa 1450 cholera.htm

[2] Dao, S., Konaté, I., Alassane, A.O., Sacko, M., Maiga, I., Toure, K., Diarra S. and Bougoudogo, F. (2009) Les épidémies de choléra au Mali de 1995 à 2004. Santé Publique, 21, 269-263. https://doi.org/10.3917/spub.093.0263

[3] Makoutode, M.F., Diallo, V., Mongbo, E., Guevart, E. and Bazira, L. (2010) La riposte à l'épidémie de choléra de 2008 à Cotonou. Santé Publique, 22, 435-425. https://doi.org/10.3917/spub.104.0425

[4] Gbary, A.R., Dossou, J.P., Sossou, R.A., Mongbo, V. and Massougbodji, A.(2011) Aspects épidémiologiques et médico-cliniques de l'épidémie de choléra dans le département du Littoral au Bénin en 2008. Santé Publique, 23, 345-358. https://doi.org/10.3917/spub.115.0345

[5] UNICEF (2014) Ministère de la santé du Benin, données de la surveillance épidémiologique 2004-2013, choléra épidémiologie et réponse, FACTSHEET Bénin. 2. https://www.unicef.org/cholera/files/UNICEF-Cholera Factsheet-Benin-VF.pdf

[6] National Directorat of Public Heath of Benin. (2017) Plan d'endiguement du choléra 2017-2021. p. 55.

[7] Schwartz, D. (1969) La méthode statistique en médecine: Les enquêtes éthiologiques. Revue de Statistique Appliquée, 8, 5-27.

[8] WHO (2017) Cholera Weekly Epidemiological Record, 2016. No. 36, 92, 521-536. http://www.who.int/wer

[9] Le, S., Josse J. and Husson, F. (2008) Facto Mine R: An R Package for Multivariate Analysis. Journal of Statistical Software, 25, 18-21. http://www.jstatsoft.org/v25/i01

[10] R Development Core Team (2017) A Language and Environment for Statistical Computing. R Foundation for Statistical Computing, Vienna, Austria. https://www.r-project.org/

[11] UNICEF (2016) Situation of the Cholera Outbreak in DRC. https://reliefweb.int/sites/reliefweb.int/files/resources/327545263-DRC-Factsheet-C holera-Outbreak-October-2016.pdf

[12] Ndour, C.T., Manga, N.M., Kâ, R.C., Dia/Badiane, N.M., Fortez, L., Seydi, M., Soumaré, M., Sow, A.I., Diop, B.M. and Sow, P.S. (2006) L'épidémie de choléra de 2004 à Dakar: Aspects épidémiologiques, Cliniques et Thérapeutiques. Médecine Tropical, 66, 33-38.

[13] Dray, X., Dray-Spira, R., Mattera, D., Bougere, J. and Garnotel, E. (2002) Une épidémie de choléra à Djibouti (Mai 2000-Janvier 2001). Médecine Tropical, 62, 502-497.

[14] Khazaei, H.A., Rezaei, N., Bagheri, G.R. and Moin, A.A.A. (2005) Six Year Study on Vibrio cholerae in Southeastern Iran. Journal of Infectious Diseases, 58, 10-18.

[15] Boutin, J.P. and Pages, F. (2000) Spécificités du choléra de l'enfant. Encyclopédie Pratique de Médecine, 8, 3-11.

[16] OMS (2004) Flambées de choléra: Evaluation des mesures mises en œuvre en cas de flambée et amélioration de la préparation. Genève, 88.

[17] Dunkle, S.E., Mba-Jonas, A., Loharikar, A., Fouché, B., Peck, M., Ayers, T. and Tappero, J.W. (2011) Epidemic Cholera in a Crowded Urban Environment, Port-au-Prince, Haiti. Emerging Infectious Diseases, 17, 2143-2146. https://doi.org/10.3201/eid1711.110772

[18] Hill, V.R., Cohen, N., Kahler, A.M., Jones, J.L., Bopp, C.A., Marano, N. and Gómez, 
G.A. (2011) Toxigenic Vibrio cholerae O1 in Water and Seafood, Haiti. Emerging Infectious Diseases, 17, 2147-2150. https://doi.org/10.3201/eid1711.110748

[19] O’Connor, K.A., Cartwright, E., Loharikar, A., Routh, J., Gaines, J., Fouché, M.D.B. and Roels, T.H. (2011) Risk Factors Early in the 2010 Cholera Epidemic, Haiti. Emerging Infectious Diseases, 17, 2136-2138.

https://doi.org/10.3201/eid1711.110810

[20] Legba, C.S., Yabi, I., Azonhe, T. and Osseni, A.A. (2017) Analyse Des Déterminants du Choléra Dans la Ville De Djougou Au Bénin. European Scientific Journal, 13, 171-184. https://doi.org/10.19044/esj.2017.v13n18p171

[21] Jaureguiberry, S., Hentgen, V., Raholiniana, N., Rasolomahera, D. and Belec, M. (2001) Le choléra à Tamatave (Madagascar) Février-Juillet 2000: Caractéristiques épidémiologiques. CERF/ Santé, 11, 73-78.

[22] Fournier, J.M. and Quilici, M.L. (2007) Choléra. La Presse Médicale, 36, 727-739. https://doi.org/10.1016/j.lpm.2006.11.029

[23] Robert-Pillot, A., Guénolé, A., Lesne, J., Delesmont, R., Fournier, J.M. and Quilici, M.L. (2000) Occurrence of the $t d h$ and trh Genes in Vibrio parahaemolyticus isolates from Waters and Raw Shellfish Collected in Two French Coastal Areas and from Seafood Imported into France. International Journal of Food Microbiology, 91, 319-325. https://doi.org/10.1016/j.ijfoodmicro.2003.07.006

[24] Tarantola, A., Ioos, S., Rotureau, B., Paquet, C., Quilici, M.L. and Fournier, J.M. (2007) Retrospective Analysis of the Cholera Cases Imported to France from 1973 to 2005. Journal of Travel Medicine, 14, 209-214. https://doi.org/10.1111/j.1708-8305.2007.00129.x 